\title{
LETTERS
}

\section{Most important risk factor missing from COPD score}

Speculating that using the Ottawa chronic obstructive pulmonary disease (COPD) Risk Scale (OCRS) "should lead to a decrease in unnecessary admissions and unsafe discharges" ${ }^{1}$ is interesting. However, the OCRS omits the most important risk factor clinicians should consider when deciding whether or not to admit a person with an exacerbation of COPD the social support and help the person has at home. The salient question is, Will this patient be able to manage their condition in that setting? Scores never seem to include this item.

The OCRS and the accompanying editorial emphasize that comorbidities are a large determinant of serious outcomes of exacerbations of COPD. ${ }^{1,2}$ Physicians are well advised to consider both a patient's multiple morbidities and social situation in admission decisions.

Stiell and colleagues ${ }^{1}$ speculated that the use of the score should lead to a decrease in unnecessary admission to hospital, whereas the editorial ${ }^{2}$ noted that depending on the cut-off selected, use of the ORCS may increase the rate of admissions overall. This assumes that clinicians follow guidelines and scores literally. They do not. 3,4
One further point: as someone who has spent a long time working at "the coal face" in the emergency department of a busy hospital, I struggle with and feel great pressure to avoid "unnecessary" admissions every shift I work. Unnecessary admission is a pejorative label, frequently used in metrics and dashboards by health planners and administrators. It is usually determined retrospectively, present in the eye of the beholder and used as rhetorical, value-laden, discourse.

\section{Don Eby MD PhD}

Emergency physician, Grey Bruce Health Services, Owen Sound, Ont.

- Cite as: CMAJ 2019 April 1;191:E370. doi: 10.1503/cmaj.71663

\section{References}

1. Stiell IG, Perry JJ, Clement CM, et al. Clinical validation of a risk scale for serious outcomes among patients with chronic obstructive pulmonary disease managed in the emergency department. CMAJ 2018;190:E1406-13.

2. Flegel K, Stanbrook MB. To keep patients with COPD out of hospital, look beyond the lungs. CMAJ 2018;190:E1402-3.

3. Eby D. Physicians don't follow guidelines: What are we to do? CMAJ 2016;188:217.

4. Mercuri M, Sherbino J, Sedran RJ, et al. When guidelines don't guide: the effect of patient context on management decisions based on clinical practice guidelines. Acad Med 2015;90:191-6.

Competing interests: None declared. 